\title{
ATLAS DO ZOOPLÂNCTON DOMINANTE NO BAIXO ESTUÁRIO DO RIO ITAJAÍ-AÇU, SANTA CATARINA, BRASIL: COPEPODA E CLADOCERA
}

\author{
Veado, L. D.; Sant’ana, B.S. \& Resgalla Jr., C. \\ CTTMar/UNIVALI - Cx. P. 360, Itajaí, 88.302-202, SC \\ ludmillaveado@gmail.com; cresgalla@univali.br
}

\begin{abstract}
Veado, L. D.; Sant'ana, B.S. \& Resgalla Jr., C. 2010. Atlas of the dominant zooplankton in the lower estuary of the Itajaí-açu river, Santa Catarina, Brazil. Braz. J. Aquat. Sci. Technol. 14(2): 79-93. ISSN 1808-7035. The Itajaí-açu river basin is the most extensive basin in the State of Santa Catarina, covering an area of $15,500 \mathrm{Km}^{2}$, and it houses an important industrial park of the South of Brazil. The estuarine region receives sediments and pollutants from the entire basin, with an area characterized by high demographic density and intense industrial and fishing activity, making this a critical area for the study of biological indicators. The objective of this study was to present a checklist of the zooplankton species in the estuary of the Itajaí-açu river, identifying the groups of species occurring in the different hydrological domains of the estuary and the morphological description of the dominant species, as the basis for future studies of the group in the region. The zooplankton community was investigated in 131 samples obtained between 2005 and 2007, at 7 collection points in the lower estuary of the Itajaí-açu river. The zooplankton consisted of 13 main taxonomic groups and 132 identified taxa. Three associations of species were identified: (a) the limnic community, dominated by the Cladocerans Bosmina longirostris, Camptocercus dadayi, Ceriodaphnia quadrangula, Ilyocryptus spinifer and Moina minuta and by the Copepods Eucyclops serrulatus, (b) the marine community comprised of the Copepods Acartia lilljeborgi, Centropages velificatus, Oithona ovalis, Oithona plumifera, Paracalanus quasimodo and Temora turbinata, and the Cladocerans Penilia avirostris and Pseudoevadne tergestina, and (c) the mixohaline group, comprised of Copepods, Pseudodiaptomus acutus and Pseudodiaptomus richardi.
\end{abstract}

Keywords: zooplankton, morphology, estuary, hydrology, South of Brazil.

\section{INTRODUÇÃO}

A bacia hidrográfica do rio Itajaí-açu é a mais extensa do estado com cerca de $15.500 \mathrm{~km}^{2}$, sendo o seu sistema estuarino, o mais importante da costa catarinense (Schettini et al., 1998). O estuário do rio Itajaí-açu é regulado pelas condições fluviais que atuam conforme os fenômenos meteorológicos, como a pluviosidade, típica de clima subtropical úmido ou mesotérmico (Comitê do Itajaí, 2004) e aos efeitos das marés e dos ventos, tornando a circulação estuarina, ainda mais complexa (Schettini \& Carvalho, 1998).

O sistema estuarino tem uma extensão total de $70 \mathrm{~km}$. Entretanto, a influência da salinidade, o que caracteriza o estuário propriamente dito, é observada a $30 \mathrm{~km}$ a montante da desembocadura (Rörig, 2005) devido à amplitude de maré de sizígia de 1,2 $\mathrm{m}$ e aos regimes pluviométricos (Schettini et al., 1998).

O baixo estuário destaca-se pelo contingente populacional, pelo desenvolvimento econômico e pelo turismo e recebe toda a carga sedimentar e de poluentes a montante da bacia. Apresenta ainda uma área portuária com atividade pesqueira e industrial, o que caracteriza um importante ambiente para estudos de indicadores ecológicos.
A comunidade planctônica, com suas características como as flutuações na composição de espécies, ciclo de vida curto e a grande capacidade de dispersão têm sido consideradas como as respostas mais rápidas as variações naturais e às perturbações antrópicas nos ecossistemas aquáticos (Schindler, 1987). Em função disto, é importante identificar espécies zooplanctônicas com vistas a compreender a estrutura biológica e as estratégias de fluxo de energia ao longo do sistema aquático, assim como interpretar as suas alterações.

Somente a partir de 1998 foram realizados estudos sobre as condições hidrológicas, químicas e do plâncton na desembocadura do rio Itajaí-açu (SC) e a influência da pluma de água doce sobre a região costeira, incluindo ainda um estudo na região de Blumenau que enfatizou o zooplâncton límnico do rio (Schettini et al., 1998 e 2005, Rörig et al., 2003 e Resgalla Jr. et al., 2008, Serafim-Junior et al., 2006). Mesmo com estes trabalhos voltados para a região do rio Itajaí-açu, o conhecimento da comunidade zooplanctônica límnica e estuarina do rio Itajaí-açu ainda é incipiente.

Este trabalho teve como objetivo apresentar um cheklist das espécies zooplanctônicas ocorrentes no baixo estuário do rio Itajaí-açu, com a identificação dos 
grupos de espécies ocorrentes nas diferentes feições hidrológicas do estuário e a descrição morfológica das espécies dominantes servindo como referencial para estudos futuros com a comunidade zooplanctônica do estuário.

\section{MATERIAL E MÉTODOS}

A área de estudo envolve o setor do baixo estuário do rio Itajaí-açu, especificamente a área de atuação do Porto de Itajaí e suas adjacências. Seus limites encontram-se a montante do rio Itajaí-mirim e a jusante em frente à praia de Navegantes (Figura 1).

Entre junho de 2005 a maio de 2007, foram realizadas 29 campanhas de coleta, obtendo 131 amostras de zooplâncton coletados em 7 pontos amostrais (Figura 1). Dentre as 131 amostras, 41 foram coletadas por arrastos oblíquos, integrando da superfície ao fundo da coluna d'água e 90 amostras foram coletadas por arrasto horizontal de superfície. Ambas as amostragens utilizaram rede tipo WP-2 cilindro-cônica de $200 \mu \mathrm{m}$ de tamanho de malha, $30 \mathrm{~cm}$ de diâmetro de boca e equipada com fluxômetro. As amostras assim obtidas foram imediatamente fixadas em solução de formaldeido a $4 \%$ neutralizado para análise posterior em laboratório. As amostragens foram realizadas com o auxílio de uma lancha de fibra de vidro com $5 \mathrm{~m}$ de comprimento, equipada por motor Johnson de $50 \mathrm{Hp}$ 2T de propulsão.

Foram obtidos dados de temperatura e salinidade com o uso de uma sonda multi-parâmetros YSI-6600, com medições a cada metro na coluna de água. Para as amostragens de superfície só foram utilizados dados a $0,5 \mathrm{~m}$ de profundidade enquanto para as amostragens oblíquas foram usadas as médias da salinidade para a coluna de água integrando sua variação vertical.

A triagem e a identificação das espécies ocorreram em laboratório através de análises qualitativas e quantitativas do zooplâncton. Para isto, foi utilizada câmara de contagem do tipo Bogorov sob microscópio estereoscópico, após o fracionamento da amostra total em alíquotas que variaram de 3 a $10 \%$ do total (Boltovskoy, 1981). A classificação ao menor nível taxonômico foi auxiliada pelo uso das referências de El Moor-Loureiro (1997); Dussart \& Defaye (1995); Infante (1988); Montú \& Gloeden (1986), Reid (1985) e Boltovskoy (1999).

Para a representação dos padrões de salinidade no interior do baixo estuário do rio Itajaí-açu, foram selecionados os períodos que melhor caracterizaram o domínio marinho, mixohalino e límnico segundo os critérios apresentados por Watanabe (1997). Conforme o

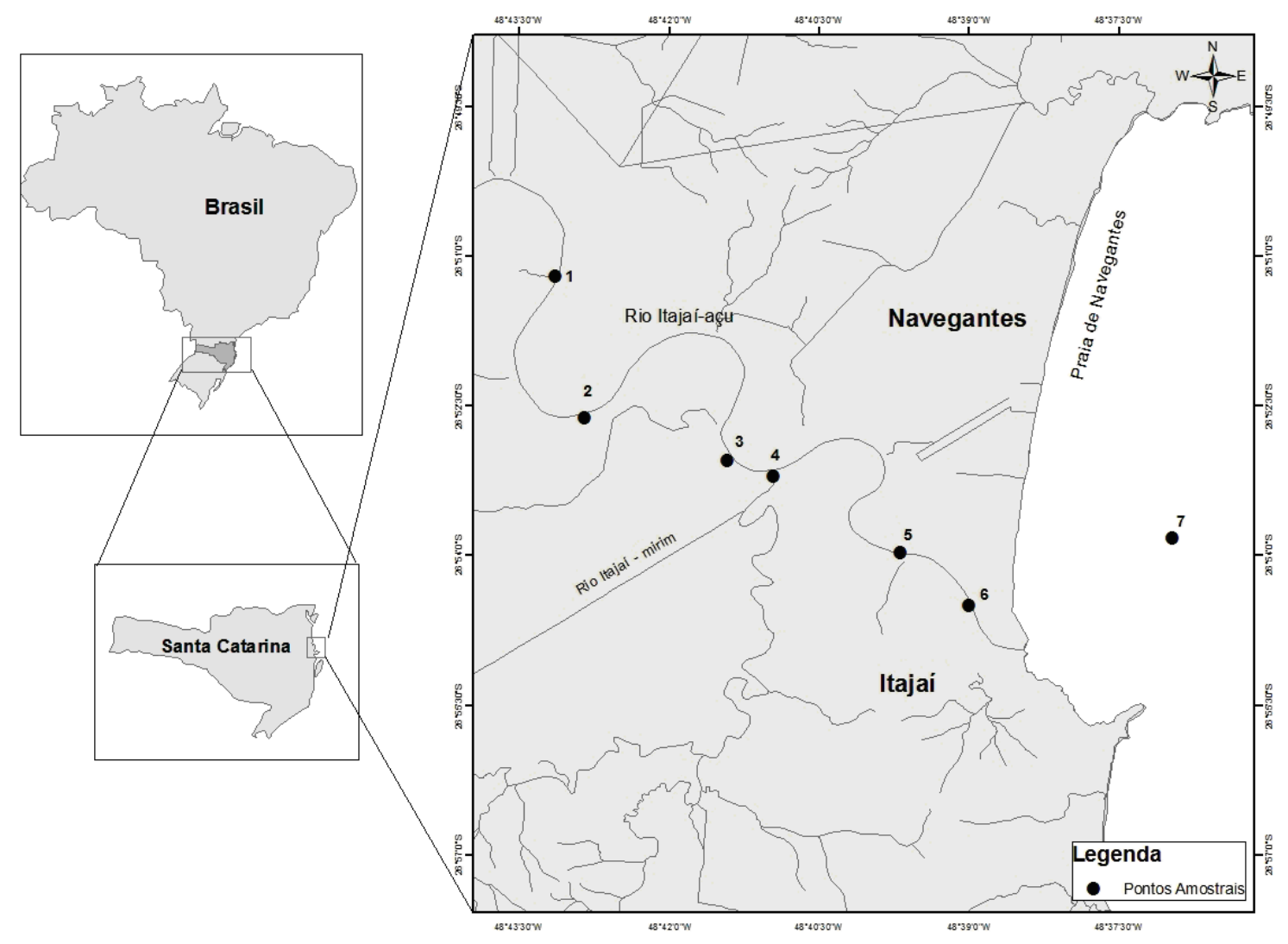

Figura 1 - Área de estudo do baixo estuário do rio Itajaí-açu com a localização dos pontos amostrais. 
período selecionado, as espécies chave para cada domínio foram escolhidas segundo a sua presença em um maior número de pontos amostrais possíveis.

Gráficos foram elaborados associando os padrões de salinidade aos padrões de ocorrência e abundância das espécies chave, procurando definir os padrões de distribuição dos organismos zooplanctônicos segundo as distintas feições hidrológicas presentes no baixo estuário do rio Itajaí-açu. O gráfico referente à amostragem em superfície apresenta os pontos amostrais \#1, \#2, \#3, \#4 e \#5 enquanto que o gráfico referente à amostragem oblíqua apresenta os pontos amostrais \#1, \#4, \#5, \#6 e \#7.

As espécies chave de cada domínio foram descritas e seus caracteres morfológicos representados para a sua fácil identificação nas amostras provenientes do baixo estuário do rio Itajaí-açu.

\section{RESULTADOS E DISCUSSÃO}

O estuário do rio Itajaí-açu apresenta uma fauna zooplanctônica diversa, constituída por 13 grandes grupos e 132 taxa distribuídos em ordens, famílias, subfamílias, gêneros e espécies (Tabela 1).

Segundo Veado (2008) a variação da temperatura no baixo estuário do rio Itajaí-açu apresenta uma sazonalidade que influencia diretamente a densidade da comunidade zooplanctônica, sendo a salinidade o fator principal controlador da composição específica do zooplâncton.

A comunidade zooplanctônica do baixo estuário do rio Itajaí-açu apresenta como espécies mais freqüentes Acartia lilljeborgi, Centropages velificatus, Eucyclops serrulatus, Oithona ovalis, Oithona plumifera, Paracalanus quasimodo, Pseudodiaptomus acutus e $P$. richardi e Temora turbinata, representando a comunidade de Copepoda. Enquanto que Bosmina longirostris, Camptocercus dadayi, Ceriodaphnia quadrangula, llyocryptus spinifer, Moina minuta, Penilia avirostris e Pseudoevadne tergestina foram os gêneros e as espécies de Cladocera mais freqüentes.

As espécies consideradas mais freqüentes constituíram as distintas comunidades aquáticas, como as comunidades marinha, mixo-halina e límnica (Tabela 2), conforme a hidrologia do sistema. Portanto, a comunidade marinha dominou o ambiente em condições de enchente (salinidade > 30), a comunidade mixohalina dominou o sistema em condições de mistura (salinidade 0,5 - 30), enquanto que a comunidade límnica dominou em condições de vazante (salinidade 0 - 0,5). Os pontos localizados a montante (pontos 1, 2 e 3) foram dominados pelas espécies consideradas límnicas, enquanto que nos pontos a jusante (pontos
Tabela 1 - A comunidade zooplanctônica com os respectivos grupos, ordens, famílias, gêneros e espécies de Copepoda e Cladocera encontrados nas distintas condições hidrológicas do baixo estuário do rio Itajaí-açu.

\begin{tabular}{|c|c|c|c|}
\hline Taxa & límnico & marinho & mixohalino \\
\hline \multicolumn{4}{|l|}{ Rotifera } \\
\hline Brachionus amphiceros & $\mathrm{x}$ & & \\
\hline \multicolumn{4}{|l|}{ Euchlanis sp } \\
\hline \multicolumn{4}{|l|}{ Cnidaria } \\
\hline \multicolumn{4}{|l|}{ Hidromedusae } \\
\hline Liriope tetraphyla & & $\mathrm{x}$ & \\
\hline \multicolumn{4}{|l|}{ Polychaeta } \\
\hline \multicolumn{4}{|l|}{ Larva } \\
\hline \multicolumn{4}{|l|}{ Mollusca } \\
\hline \multicolumn{4}{|l|}{ Bivalva (veliger) } \\
\hline \multirow{2}{*}{\multicolumn{4}{|c|}{ Gastropoda (veliger) }} \\
\hline \multirow{2}{*}{\multicolumn{4}{|c|}{ Cladocera }} \\
\hline & & & \\
\hline \multicolumn{4}{|l|}{ Ordem Onychopoda } \\
\hline \multicolumn{4}{|l|}{ Família Bosminidae Sars, 1865} \\
\hline Bosmina longirostris & $\mathrm{x}$ & & \\
\hline \multicolumn{4}{|l|}{ Bosminopsis sp } \\
\hline Bosminopsis deitersi & $x$ & & \\
\hline Família Chydoridae Stebbing, 1902 & & & \\
\hline Subfamília Chydorinae Stebbing, 1902 & & & \\
\hline Alonella sp & & & \\
\hline Chydorus sp & & & \\
\hline Chydorus eurynotus & $\mathrm{x}$ & & \\
\hline Subfamília Aloninae Frey, 1967 & & & \\
\hline Alona sp & & & \\
\hline Alona rustica & $\mathrm{x}$ & & \\
\hline Camptocercus dadayi * & $\mathrm{x}$ & & \\
\hline Euryalona orientalis & $\mathrm{x}$ & & \\
\hline Kurzia latissima & $\mathrm{x}$ & & \\
\hline Oxyurella longicaudis & $\mathrm{x}$ & & \\
\hline Família Daphniidae Straus, 1820 & & & \\
\hline Ceriodaphnia sp & & & \\
\hline Ceriodaphnia quadrangula & $x$ & & \\
\hline Daphnia laevis & $\mathrm{x}$ & & \\
\hline Simocephalus vetulus & $x$ & & \\
\hline Família llyocryptidae Smirnov, 1992 & & & \\
\hline Ilyocryptus spinifer * & $x$ & & \\
\hline Família Macrothricidae Norman \& Brady, 1867 & & & \\
\hline Macrothrix sp & & & \\
\hline Macrothrix triserialis & $\mathrm{x}$ & & \\
\hline Família Moinidae Goulden, 1968 & & & \\
\hline Moina minuta * & $\mathrm{x}$ & & \\
\hline Familia Podonidae Mordukhai-Boltovskoy, 1968 & & & \\
\hline Podon sp & & & \\
\hline Pseudoevadne tergestina * & & $\mathrm{x}$ & \\
\hline Ordem Ctenopoda & & & \\
\hline Família Sididae Baird, 1850 & & & \\
\hline Diaphanossoma birgei & $x$ & & \\
\hline Penilia avirostris * & & $\mathrm{x}$ & \\
\hline Copepoda & & & \\
\hline Naupliu & & & \\
\hline Copepodito & & & \\
\hline Ordem Calanoida & & & \\
\hline Família Acartiidae Sars, 1903 & & & \\
\hline Acartia sp & & & \\
\hline Acartia lilljeborgi * & & $\mathrm{x}$ & \\
\hline Acartia tonsa & & $\mathrm{x}$ & \\
\hline Família Centropagidae Giesbrecht, 1892 & & & \\
\hline Centropages velificatus * & & $\mathrm{x}$ & \\
\hline Família Diaptomidae Sars, 1903 & & & \\
\hline Subfamília Diaptominae & & & \\
\hline Eudiaptomus vulgaris & $x$ & & \\
\hline Família Eucalanidae Giesbrecht, 1892 & & & \\
\hline Eucalanus $\mathrm{sp}$ & & & \\
\hline Família Paracalanidae Giesbrecht, 1892 & & & \\
\hline Paracalanus sp & & & \\
\hline Paracalanus quasimodo * & & & $\mathrm{x}$ \\
\hline Parvocalanus crassirostris & & & $x$ \\
\hline
\end{tabular}


Tabela 1 (cont.)

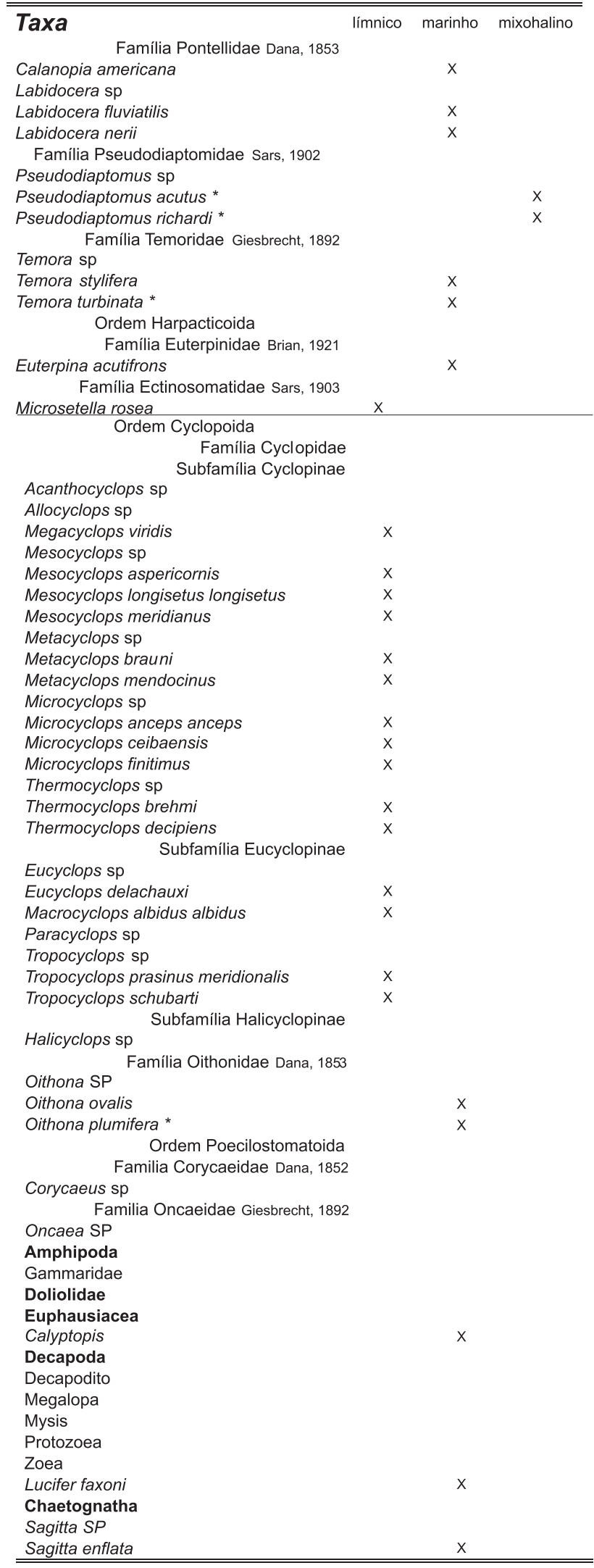

4, 5, 6 e 7), as espécies marinha e mixo-halina foram as dominantes.

Em cada comunidade, alguns organismos foram considerados espécie-chave segundo sua freqüência e dominância no ambiente. Assim, o Copepoda Acartia lilljeborgi foi a espécie-chave da comunidade marinha, dominante e freqüente no ambiente em condições de enchente (Fig. 2). A comunidade mixo-halina apresentou como espécie-chave o Copepoda Pseudodiaptomus richardi (Fig. 3) espécie mais freqüente e dominante em condições de mistura, enquanto que a comunidade límnica apresentou como espécie-chave, o Cladocera Moina minuta, sendo a mais freqüente e dominante no sistema em condições limnológicas (Fig. 4). Esta espécie apresentou alta abundância no ponto \#4, localizado em frente à desembocadura do rio Itajaí-mirim, o que pode ser resultado do aporte de água doce no meio do estuário. Segundo Veado (2008), a baixa transparência média da água, observada neste ponto amostral, pode ser reflexo do aporte de matéria orgânica proveniente do rio Itajaí-mirim ao rio Itajaí-açu.

As espécies mais freqüentes da comunidade zooplanctônica encontradas no baixo estuário do rio Itajaí-açu têm sua diagnose, ecologia e distribuição geográfica, bem como as demais literaturas que as citam, apresentadas a seguir.

\section{CLADOCERA}

Família Sididae

Espécie Penilia avirostris Dana, 1852

(Figura 5a)

\section{Diagnose}

Corpo alongado quase retangular e cabeça triangular. Carapaça transparente, bivalva com bordas ventrais com espinhos. Patas foliáceas.

\section{Ecologia}

Espécie eurihalina (10-35) e termófila $\left(20-27^{\circ} \mathrm{C}\right)$, alta densidade na primavera e no verão em áreas costeiras, alcançando o interior do baixo estuário. Ocorre em condições de enchente e indica águas quentes e eutrofizadas.

Distribuição

Literatura

Cosmopolita

Ramirez (1981); Onbé (1999). 
Braz. J. Aquat. Sci. Technol., 2010, 10(2): 79-93.

Tabela 2 - As comunidades zooplanctônicas com seus respectivos grupos e espécies dominantes encontrados no baixo estuário do rio Itajaí-açu.

\begin{tabular}{|c|c|c|c|}
\hline GRUPO & $\begin{array}{l}\text { COMUNIDADE } \\
\text { LÍMNICA }\end{array}$ & $\begin{array}{l}\text { COMUNIDADE } \\
\text { MARINHA }\end{array}$ & $\begin{array}{l}\text { COMUNIDADE } \\
\text { MIXO-HALINA }\end{array}$ \\
\hline COPEPODA & $\begin{array}{l}\text { Eucyclops serrulatus } \\
\text { (Fischer, 1851) }\end{array}$ & $\begin{array}{c}\text { Acartia lilljeborgi } \\
\text { Giesbrecht, 1889 } \\
\text { Centropages velificatus } \\
\text { (Oliveira, 1947) } \\
\text { Oithona ovalis } \\
\text { Herbest, 1955 } \\
\text { Oithona plumifera } \\
\text { Baird, 1843 } \\
\text { Paracalanus quasimodo } \\
\text { Bowman, 1971 } \\
\text { Temora turbinata } \\
\text { Dana, 1849 }\end{array}$ & $\begin{array}{c}\text { Pseudodiaptomus acutus } \\
\text { (F. Dahl, 1894) } \\
\text { Pseudodiaptomus } \\
\text { richardi } \\
\text { (F. Dahl, 1894) }\end{array}$ \\
\hline CLADOCERA & $\begin{array}{c}\text { Bosmina longirostris } \\
\text { (O.F. Müller, 1785) } \\
\text { Camptocercus dadayi } \\
\text { Stingelin, 1913 } \\
\text { Ceriodaphnia quadrangula } \\
\text { (O.F. Müller, 1785) } \\
\text { Ilyocryptus spinifer } \\
\text { Herrick, 1882 } \\
\text { Moina minuta } \\
\text { Hansen, 1899 } \\
\end{array}$ & $\begin{array}{c}\text { Penilia avirostris } \\
\text { Dana, } 1849 \\
\text { Pseudoevadne tergestina } \\
\text { (Claus, 1877) }\end{array}$ & \\
\hline
\end{tabular}
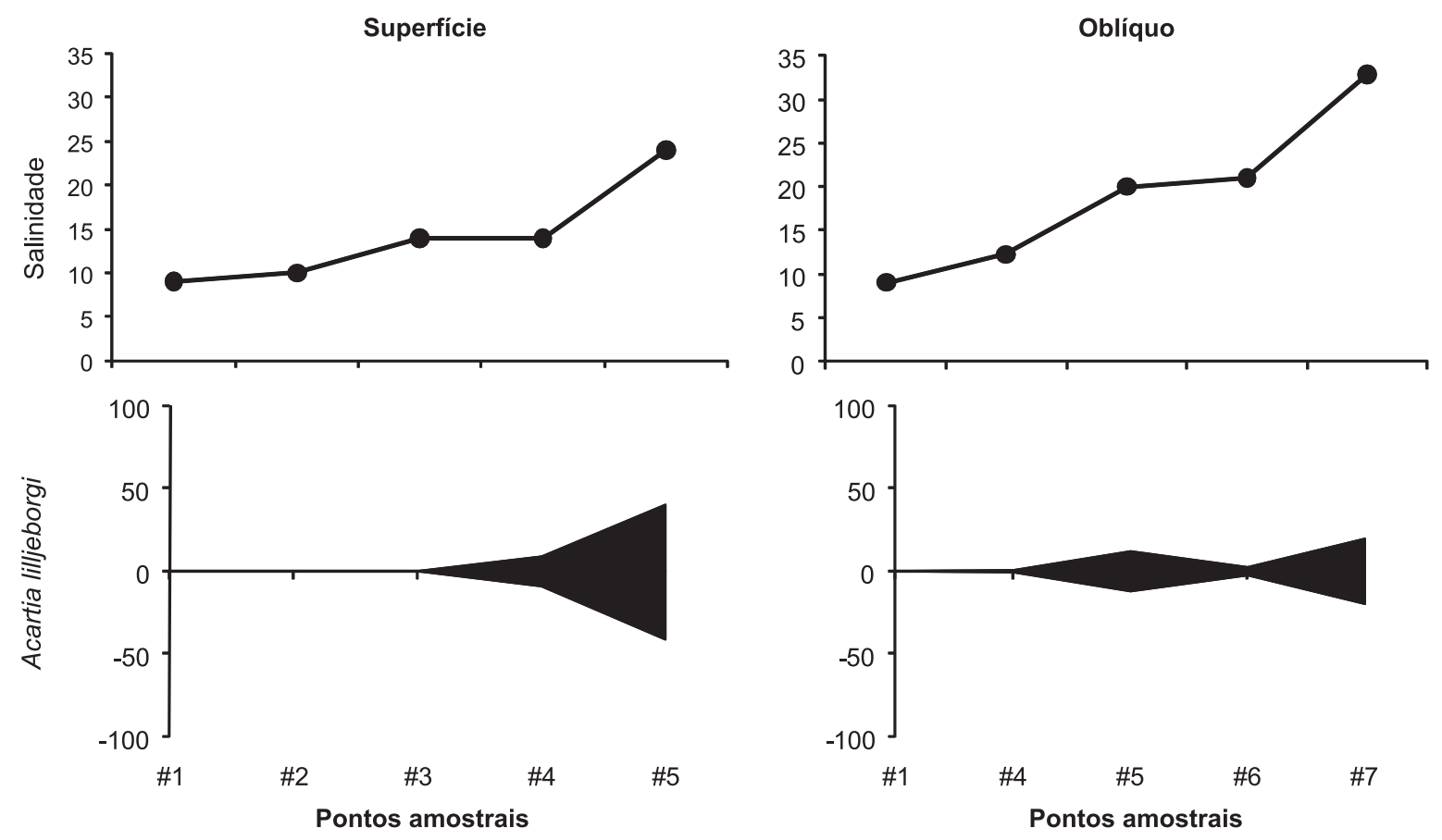

Figura 2 - Variação da salinidade e da abundância (\%) de Acartia lilljeborgi por ponto de coleta, em junho de 2006 para as amostragens em superfície e oblíquo em condições marinhas no baixo estuário do rio Itajaí-açu.

\section{Família Podonidae \\ Espécie Pseudoevadne tergestina (Claus, 1877)}

\section{Diagnose}

(Figura 5b)

Corpo oval. Borda posterior da carapaça arredondada. Exópodos das patas toráxicas 1 a 3 com 2,3 e 3 cerdas, respectivamente.

\section{Ecologia}

Espécie eurihalina (10-35) e termófila $\left(20-27^{\circ} \mathrm{C}\right)$, alta densidade na primavera e no verão, associada à Penilia avirostris. Ocorre em condições de enchente e indica águas quentes costeiras e oceânicas.

\section{Distribuição}

Águas temperadas e tropicais em ambos os hemisférios.

\section{Literatura}

Ramirez (1981); Onbé (1999). 

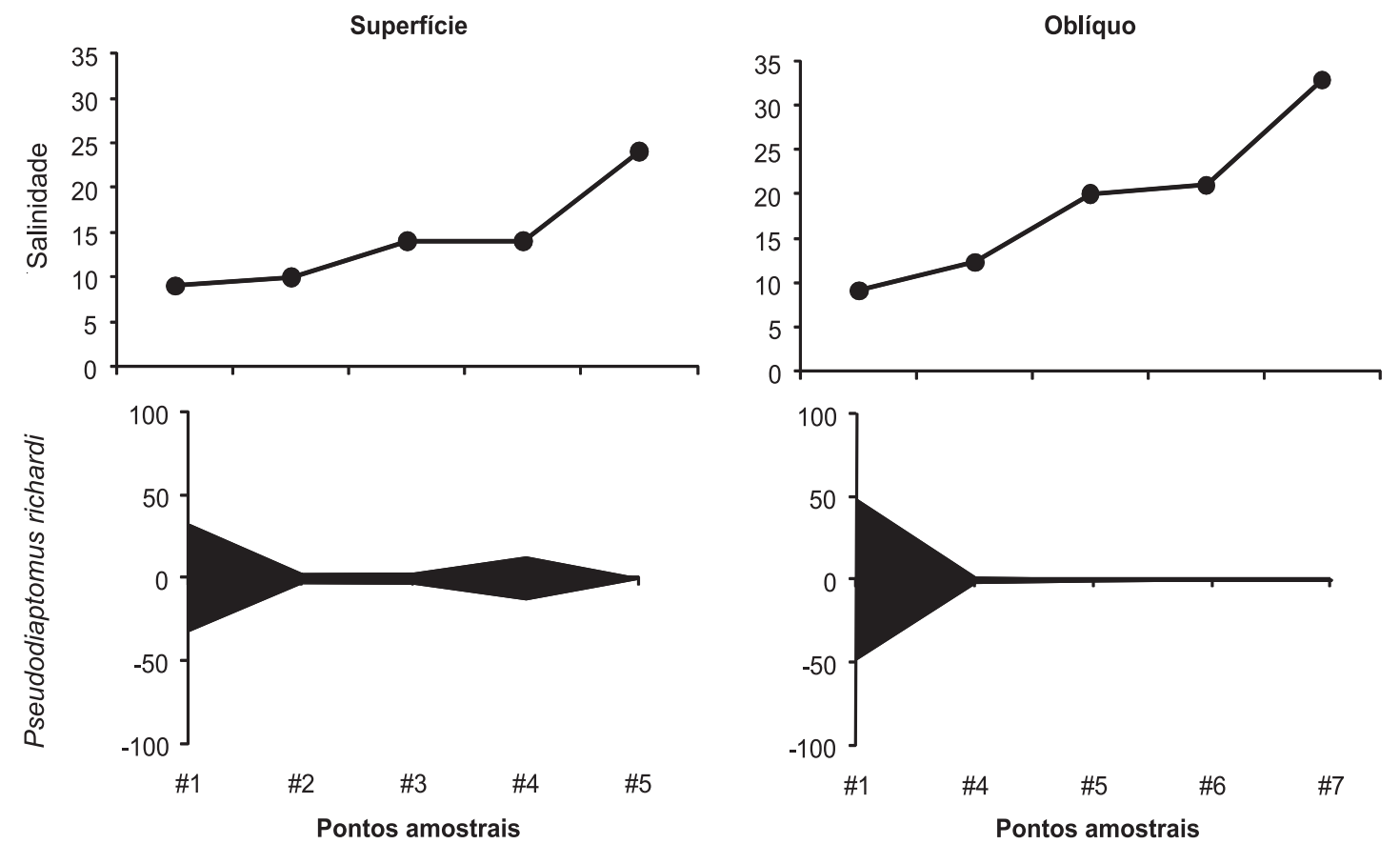

Figura 3 - Variação da salinidade e da abundância (\%) de Pseudodiaptomus richardi por ponto de coleta, em junho de 2006 no baixo estuário do rio Itajaí-açu para as amostragens em superfície e oblíquo.
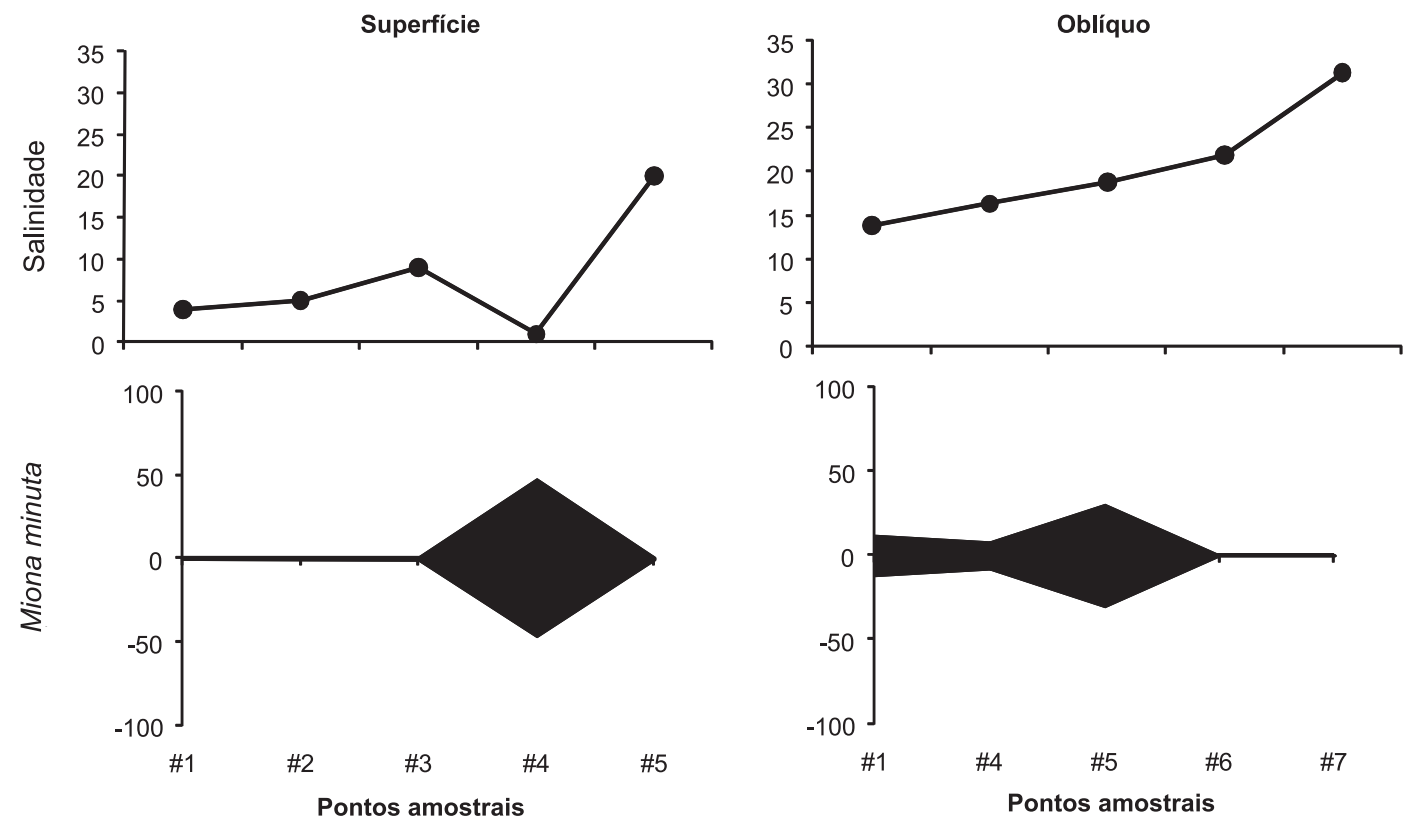

Figura 4 - Variação da salinidade e da abundância (\%) de Moina minuta por ponto de coleta, em dezembro de 2006 no baixo estuário do rio Itajaí-açu para as amostragens em superfície e oblíquo. 


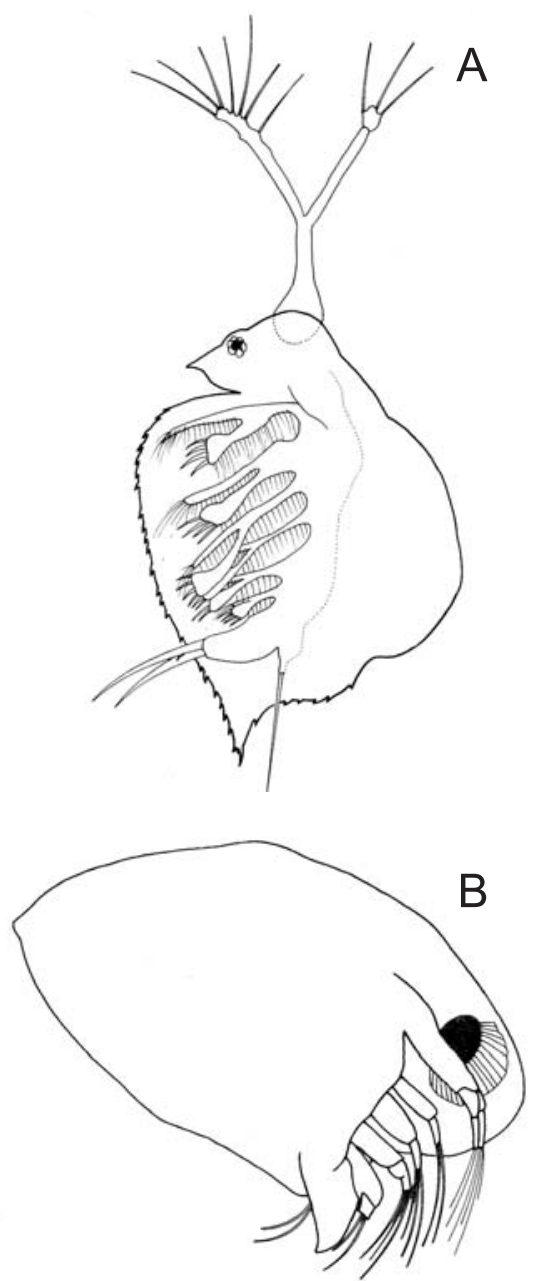

Figura 5 - (A) Penilia avirostris; (B)Pseudoevadne tergestina.

\section{Família Moinidae}

Espécie Moina minuta Hansen, 1899

(Figuras 6a e 6b)

\section{Diagnose}

Olho grande e composto. Pós-abdômem com um espinho bifurcado com ramos separados e tamanhos semelhantes (seta).

\section{Ecologia}

Espécie oligohalina (0-10) e termófila $\left(20-30^{\circ} \mathrm{C}\right)$, alta densidade na primavera e no verão. Ocorre em condições de vazante e indica águas oligo-mesotróficas.

\section{Distribuição}

Comum em ambientes dulcícolas no Brasil.

\section{Sinonímias}

Moinodaphnia brasiliensis (Pará, Stingelin, 1904)

Moina minima (Piauí, Spandl, 1926)

\section{Literatura}

El Moor-Loureiro (1997), Coelho-Botelho (2003).
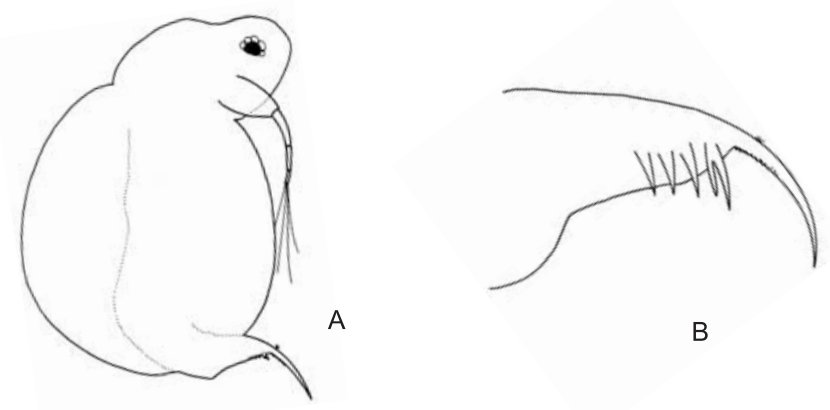

B
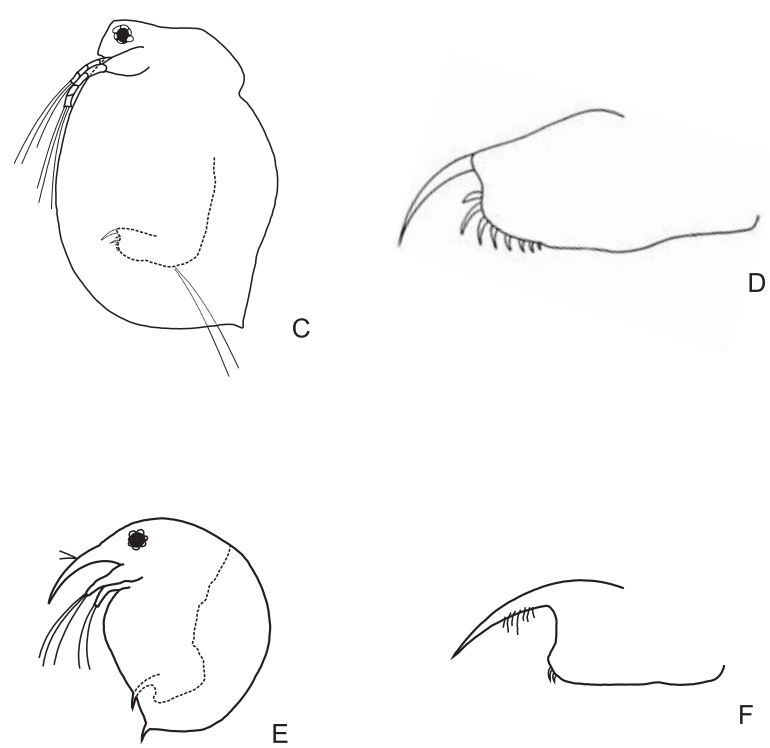

Figura 6 - (A) Moina minuta; (B) pós-abdômen; (C) Ceriodaphnia quadrangula; (D) pós-abdômen; (E) Bosmina longirostris; (F) pósabdômen.

\section{Família Daphniidae}

Espécie Ceriodaphnia quadrangula (O. F. Müller, 1785)

(Figuras 6c e 6d)

\section{Diagnose}

Corpo pequeno, cabeça angulosa em frente às antênulas. Pós-abdômen curto com 7 - 9 espinhos anais. Ecologia

Espécie oligohalina $(0-10)$ e termófila $\left(20-30^{\circ} \mathrm{C}\right)$, alta densidade no verão. Ocorre em condições de vazante e indica águas com baixo $\mathrm{pH}$.

\section{Distribuição}

Comum em ambientes dulcícolas no Brasil.

\section{Literatura}

Elmoor-Loureiro (1997), Keppeler \& Hardy (2002). 


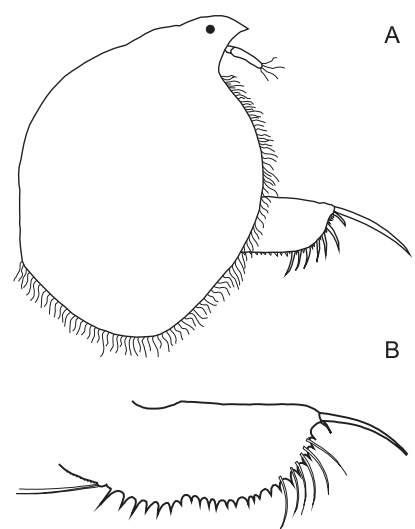

B

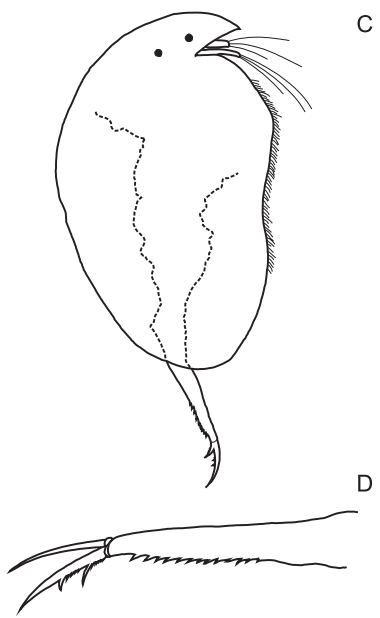

Figura 7 - (A) llyocryptus spinifer; (B) pós-abdômen; (C) Camptocercus dadayi; (D) pós-abdômen

Família Bosminidae

Espécie Bosmina longirostris (O. F. Müller, 1785)

(Figuras 6e e 6f)

\section{Diagnose}

Corpo pequeno e arredondado. Carapaça transparente. Pós-abdômem relativamente quadrado, garra terminal cilíndrica com espinhos pequenos. Borda inferior do pós-abdômem com 2 espinhos terminais pequenos.

\section{Ecologia}

Espécie oligohalina (0-10) e estenotérmica (10$20^{\circ} \mathrm{C}$ ), alta densidade na primavera. Ocorre em condições de vazante e indica condições de eutrofização.

\section{Distribuição}

Cosmopolita em ambientes dulcícolas no Brasil.

\section{Literatura}

Elmoor-Loureiro (1997); Coelho-Botelho (2003).

\section{Observações}

Os registros desta espécie no Brasil podem ser duvidosos, sendo facilmente confundida com Bosmina freyi. Checar também poro cefálico e base da antena (Kotov et al., 2009).
Família Ilyocryptidae

Espécie llyocryptus spinifer Herrick, 1882

(Figuras 7a e 7b)

\section{Diagnose}

Corpo ovalado, cabeça pequena e triangular. Carapaças lisas com margem ventral com cerdas pontiagudas. Pós-abdômem largo com cerca de 24 dentículos e 6 espículas laterais.

Ecologia

Espécie oligohalina (0-10) e euritérmica (10$28^{\circ} \mathrm{C}$ ), alta densidade na primavera e no verão. Ocorre em condições de vazante, indicadora de poluição a partir de deformidades morfológicas em indivíduos de populações naturais.

\section{Distribuição}

Encontrada em ambientes dulcícolas do norte ao sul do Brasil.

\section{Sinonímias}

Ilyocryptus halyi (Brady, 1886)

Ilyocryptus longiremis (Sars, 1888; Pernambuco, Brehm, 1937 e 1938; Schubart, 1942; São Paulo, Sars, 1901) 1939)

Ilyocryptus tetraspinatus (São Paulo, Bergamin,

Acanthocercus inmundus (Müller, 1895)

\section{Literatura}

Montú \& Gloeden (1986); Elmoor-Loureiro (1997).

\section{Observação}

Recomenda-se também checar labro e base da antena (Elmoor-Loureiro et al., 2004).

\section{Família Chydoridae}

Subfamília Aloninae

Espécie Camptocercus dadayi Stingelin, 1913

(Figuras 7c e 7d)

\section{Diagnose}

Corpo oval alongado. Pós-abdômem longo e estreito com cerca de 13 dentículos alongados e triangulares. Garra longa com um arranjo de espículas seguido por 1 dentículo forte. Espinho basal curto e fino com espículas em sua base.

\section{Ecologia}

Espécie oligohalina (0-10) e euritérmica (10$28^{\circ} \mathrm{C}$ ), alta densidade na primavera e no verão. Ocorre em condições de vazante.

\section{Distribuição}

Encontrada em ambientes dulcícolas do norte ao sul do Brasil.

\section{Sinonímias}

Ilyocryptus halyi (Brady, 1886)

Ilyocryptus longiremis (Sars, 1888; Pernambuco, Brehm, 1937 e 1938; Schubart, 1942; São Paulo, Sars, 1901) 

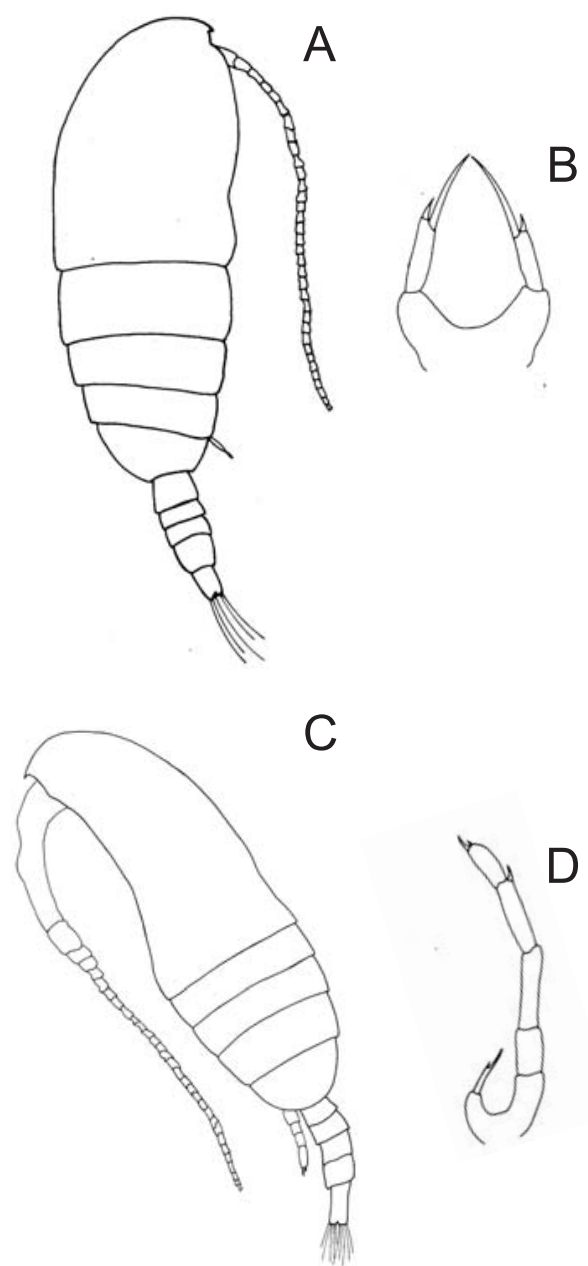

Figura 8 - Paracalanus quasimodo - (A) fêmea; (B) quinta pata da fêmea; (C) macho; (D) quinta pata do macho.

Ilyocryptus tetraspinatus (São Paulo, Bergamin,

\section{Literatura}

Acanthocercus inmundus (Müller, 1895)

Montú \& Gloeden (1986); Elmoor-Loureiro (1997).

\section{COPEPODA}

\section{Família Paracalanidae}

Espécie Paracalanus quasimodo Giesbrecht, 1892

(Figura 8)

\section{Diagnose}

Corpo arredondado e pequeno com prossoma e urossoma nitidamente separados. A fêmea apresenta quinta pata (P5) simétrica com espinhos terminais delgados e desiguais. O macho apresenta P5 assimétrica.

\section{Ecologia}

Espécie eurihalina $(0-35)$ e euritérmica $\left(15-28^{\circ} \mathrm{C}\right)$, ocorre ao longo do ano em águas neríticas e costeiras. No estuário do rio Itajaí-açu é umas das espécies mais freqüentes e dominantes ao longo do ano com maiores
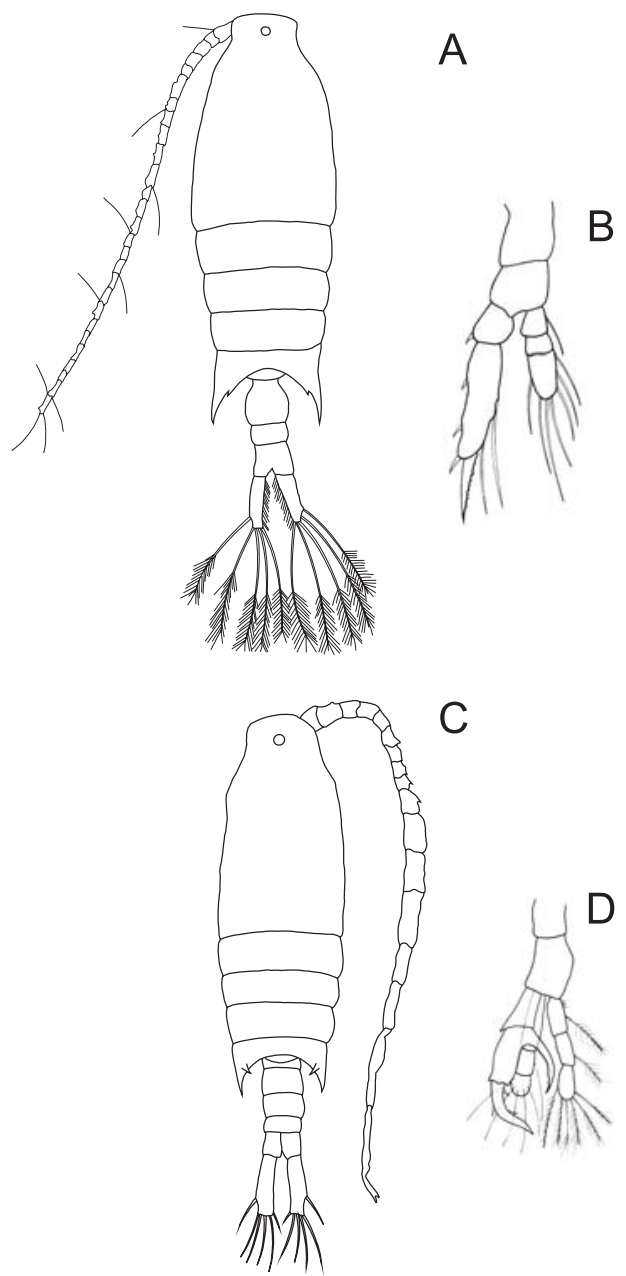

Figura 9 - Centropages velificatus - (A) fêmea; (B) quinta pata da fêmea; (C) macho; (D) quinta pata do macho.

densidades em condições de mixohalinização. Indica presença de Água Tropical com altas temperaturas.

\section{Distribuição}

Ampla distribuição em águas tropicais no oceano Atlântico. No Brasil ocorre nas costas nordeste, central e sul, alcançando o norte do Atlântico $\left(33^{\circ} \mathrm{N}\right)$.

\section{Literatura}

Bjornberg (1981); Bradford-Grieve, et al (1999); Dias \& Araujo (2006), Resgalla, et al. (2008).

\section{Família Centropagidae}

Espécie Centropages velificatus Giesbrecht, 1892

\section{Diagnose}

(Figura 9)

A fêmea e o macho apresentam olho ventral e dois espinhos em cada lado na porção final do prossoma. A fêmea apresenta margem interna do ramo caudal hirsuta. A antênula direita do macho é geniculada. 


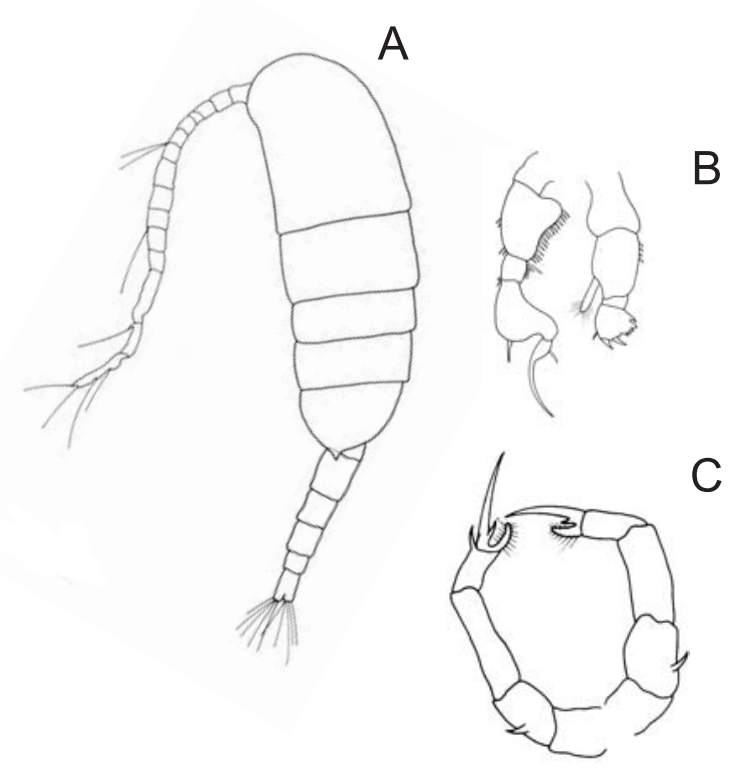

Figura 10 - Pseudodiaptomus acutus - (A) macho; (B) quinta pata do macho; (C) quinta pata da fêmea.

\section{Ecologia}

Espécie eurihalina (20-35) e termófila $\left(20-28^{\circ} \mathrm{C}\right)$. Epipelágica, comum em águas costeiras e de plataforma. Alta densidade em condições de enchente.

\section{Distribuição}

Ampla distribuição em águas tropicais e subtropicais nos oceanos Atlântico, Pacífico e Índico. No Brasil ocorre nas costas norte, nordeste, central e sul.

\section{Sinonímias}

Catopia furcata (Dana, 1852).

\section{Literatura}

Centropages furcatus (Dana, 1852, Brady, 1883).

Bjornberg (1981); Bradford-Grieve, et al (1999);

Dias \& Araujo (2006).

\section{Família Pseudodiaptomidae \\ Espécie Pseudodiaptomus acutus Sars, 1902}

\section{Diagnose}

(Figura 10)

Prossoma termina com espinhos robustos na borda posterior. A fêmea apresenta quinto par de patas assimétrico. P5 com o lado esquerdo mais curto que 0 direito e com espinhos finos laterais externos. Finaliza com garra terminal curta apresentando espinho externo e uma prolongação plumosa interna. O macho apresenta uma das antenas geniculada. Quinto par de patas assimétrico, sendo a esquerda mais curta que a direita. Último segmento da pata esquerda pequeno com 2 espinhos distais de tamanho semelhante.
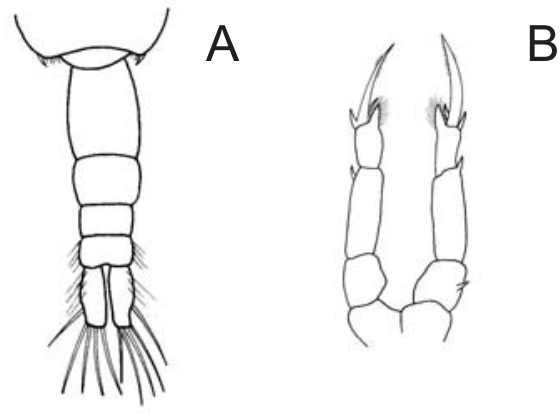

B
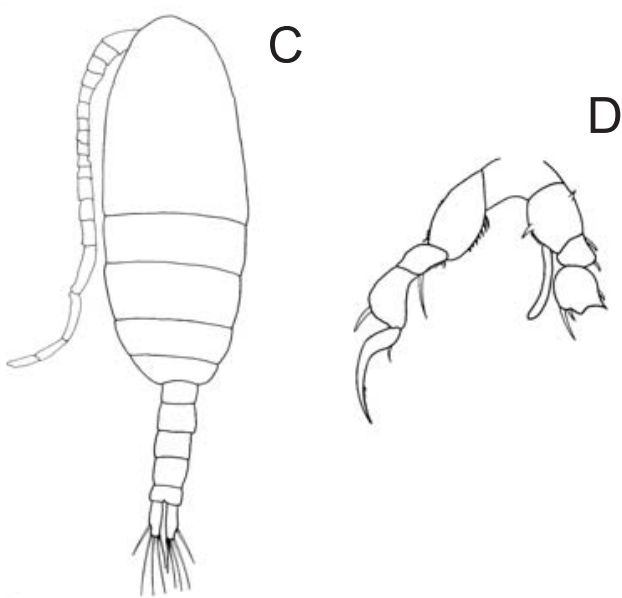

Figura 11 - Pseudodiaptomus richardi - (A) urossoma da fêmea; (B) quinta pata da fêmea; (C) macho; (D) quinta pata do macho.

\section{Ecologia}

Espécie eurihalina $(0-28)$ e termófila $\left(18-24^{\circ} \mathrm{C}\right)$. Estuarina e epipelágica, comum em águas de baías e mangues. Alta densidade nos meses de outono e inverno e indica condições de mixohalinização no baixo estuário do rio Itajaí-açu.

Distribuição

Ocorre na desembocadura do rio Amazonas a costa sul do Brasil.

\section{Sinonímias}

Weismanella acuta (Dahl, 1894)

Schmakeria acuta (Poppe \& Mrazek, 1895)

\section{Literatura}

Bjornberg (1981); Bradford-Grieve, et al (1999) e Montú \& Gloeden (1986).

\section{Família Pseudodiaptomidae}

Espécie Pseudodiaptomus richardiSars, 1902

(Figura 11)

\section{Diagnose}

Porção final do prossoma arredondado. Quinto par de patas na fêmea é assimétrico. A pata esquerda um pouco mais longa que a direita com garra terminal 
mediana, curvada e com espinho basal na margem interna. O macho apresenta uma das antenas geniculada. Quinto par de patas assimétrico, sendo a esquerda mais curta que a direita. Último segmento da pata esquerda apresenta 2 espinhos distais de tamanhos distintos.

\section{Ecologia}

Espécie eurihalina (0-28) e termófila $\left(15-20^{\circ} \mathrm{C}\right)$. Estuarina e epipelágica, comum na desembocadura de rios e regiões de mangue. Alta densidade nos meses de outono e inverno e indica condições de mixohalinização no baixo estuário do rio Itajaí-açu.

\section{Distribuição}

Ocorre na América do Sul $\left(0^{\circ}-30^{\circ} \mathrm{S}\right)$, desde a desembocadura do rio Amazonas a desembocadura do rio da Prata.

\section{Sinonímias}

Weismanella richardi (Dahl, 1894)

Schmakeria richardi (Poppe \& Mrazek, 1895)

\section{Literatura}

Bjornberg (1981); Bradford-Grieve, et al (1999) e Montú \& Gloeden (1986).

\section{Família Temoridae}

Espécie Temora turbinata Giesbrecht, 1982

(Figura 12)
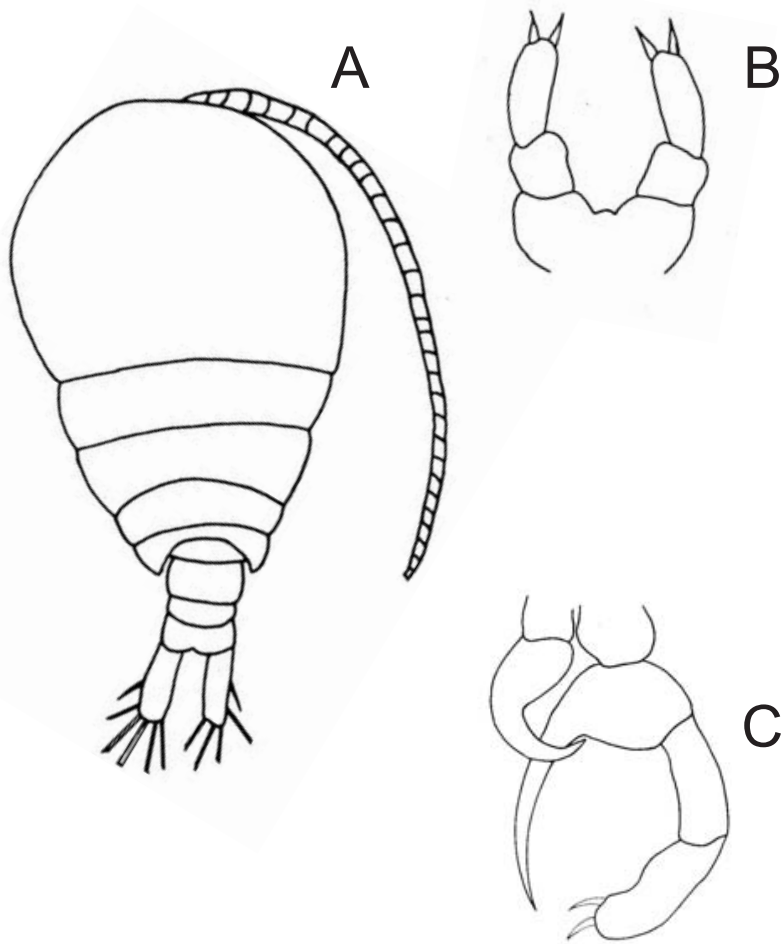

Figura 12 - Temora turbinata - (A) fêmea; (B) quinta pata da fêmea; $(C)$ quinta pata do macho.

\section{Diagnose}

Corpo arredondado em forma de escudo. Prossoma e urossoma nitidamente separados. Porção final do prossoma arredondada. A fêmea apresenta quinto par de patas reduzido e simétrico. O macho apresenta P5 assimétrica.

\section{Ecologia}

Espécie eurihalina (10-32) e termófila $\left(22-27^{\circ} \mathrm{C}\right)$, costeira e oceânica. Comum ao longo do ano com maiores densidades nos meses de primavera e verão e em condições de enchente. Indica presença da Água Tropical em altas temperaturas.

\section{Distribuição}

Apresenta ampla distribuição em águas tropicais e subtropicais dos oceanos Atlântico, Pacífico e Índico. Considerada invasora na costa brasileira.

\section{Literatura}

Bjornberg (1981); Bradford-Grieve, et al (1999); Dias \& Araujo (2006); Lopes (2004), Resgalla, et al. (2008).

\section{Família Acartiidae}

Espécie Acartia lilljeborgi Sars, 1903

(Figura 13)

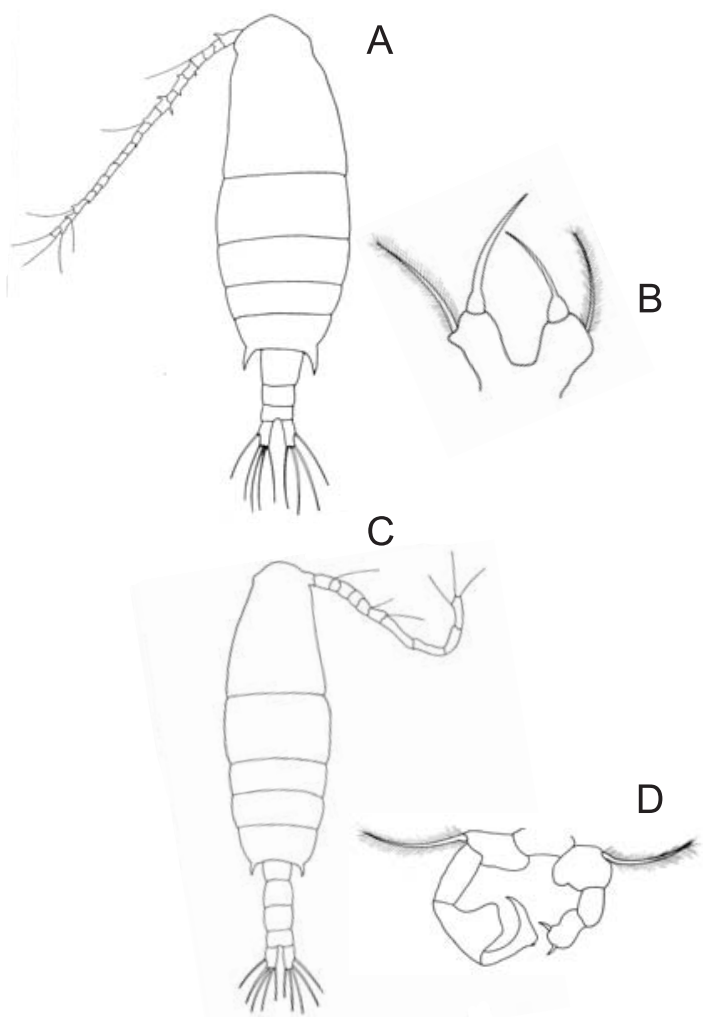

Figura 13 - Acartia lilljeborgi - (A) fêmea; (B) quinta pata da fêmea; (C) macho; (D) quinta pata do macho. 


\section{Diagnose}

Corpo alongado, estreitando-se nas porções anterior e posterior do prossoma, nitidamente separado do urossoma. Margem posterior do prossoma apresenta espinhos robustos tanto na fêmea como no macho. Quinto par de patas da fêmea simétrico e reduzido com espinho distal apresentando cerdas. P5 assimétrica no macho que apresenta uma das antenas dobradas.

\section{Ecologia}

Espécie eurihalina (0-35) e termófila $\left(19-27^{\circ} \mathrm{C}\right)$, epipelágica, estuarina e costeira, alcançando águas quentes de plataforma. No estuário do rio Itajaí-açu é uma das espécies mais freqüentes e dominantes ao longo do ano com maiores densidades em condições de enchente.

\section{Distribuição}

Ampla distribuição no oceano Atlântico Sul, ao longo da costa brasileira. Encontrada nas costas nordeste, central e sul do Brasil.

\section{Literatura}

Bjornberg (1981); Bradford-Grieve, et al (1999);

Dias \& Araujo (2006).

\section{Família Oithonidae}

Espécie Oithona ovalis Dana, 1853

(Figuras 14a e 14b)

\section{Diagnose}

O prossoma e o urossoma são nitidamente separados e o prossoma é curto. Rostro visível dorsalmente de forma triangular na fêmea. O macho apresenta antena direita geniculada.

\section{Ecologia}

Espécie eurihalina (10-34) e termófila $\left(21-28^{\circ} \mathrm{C}\right)$, típica de águas quentes de manguezais e costeiras com maior densidade em condições de enchente.

\section{Distribuição}

Distribui-se do norte ao sul do Brasil em áreas de manguezais.

\section{Sinonímias}

Oithona brevicornis (Gaudy, 1963)

\section{Literatura}

Oithona minuta (Bjornberg, 1963)

Bjornberg (1981); Montú \& Gloeden (1986); Bradford-Grieve, et al (1999); Dias \& Araujo (2006).

\section{Família Oithonidae}

Espécie Oithona plumifera Dana, 1853

\section{Diagnose}

(Figura 14c)

Corpo alongado e estreito com prossoma e urossoma nitidamente separados. Rostro agudo e visí-
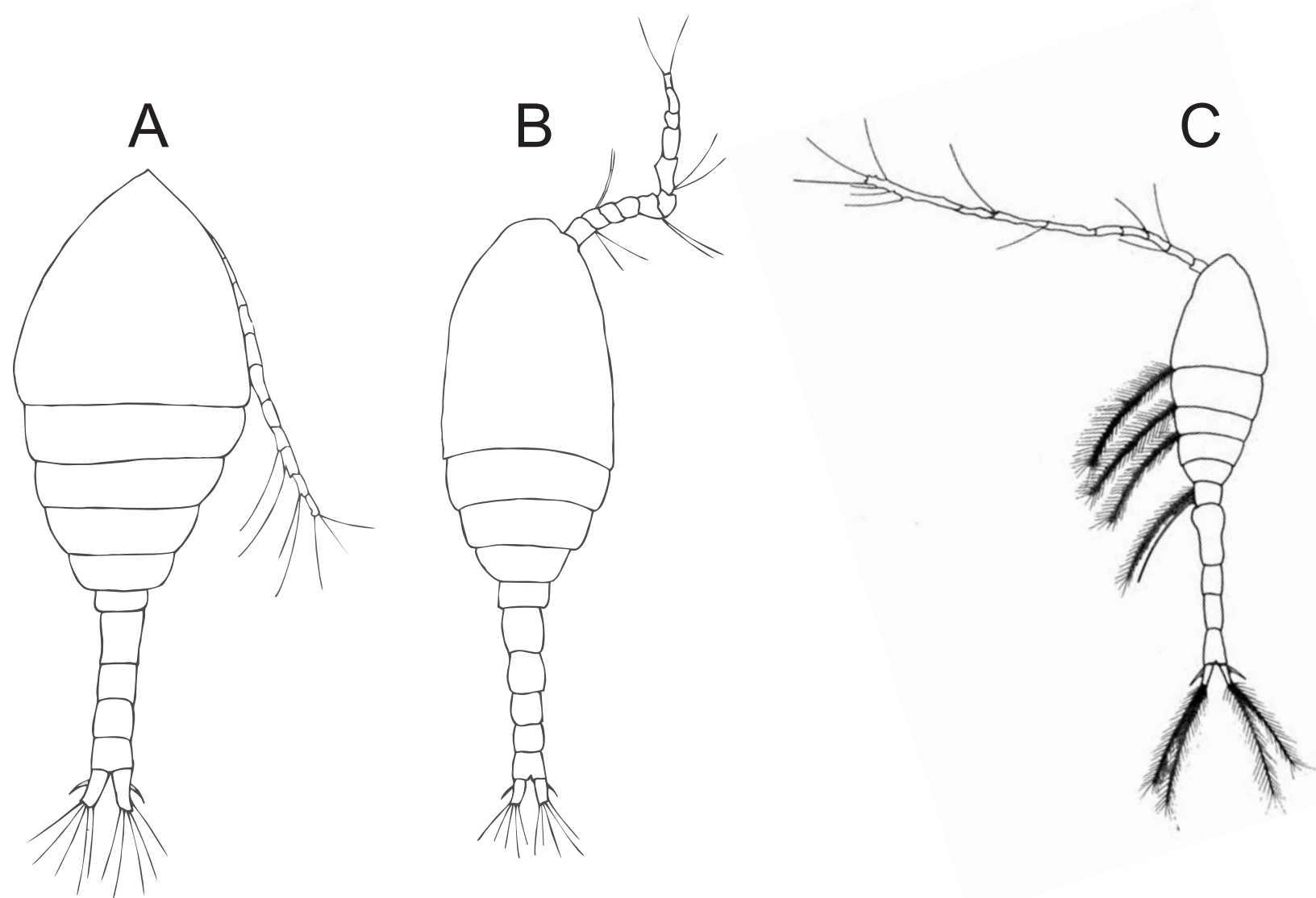

Figura 14 - Oithona ovalis - (A) fêmea; (B) macho; (C) Oithona plumifera - fêmea. 
vel dorsalmente na fêmea. Antena com cercas longas e delicadas.

\section{Ecologia}

Espécie estenohalina (20-33) e estenotérmica $\left(20-26^{\circ} \mathrm{C}\right)$, epipelágica presente em águas costeiras e oceânicas. Maior densidade em condições de enchente.

\section{Distribuição}

Ampla distribuição em águas tropicais e subtropicais nos oceanos Atlântico, Pacífico e Índico.

\section{Sinonímias}

Oithona spinirostris (Claus, 1863)

Oithona challengeri (Brady, 1900)

\section{Literatura}

Bjornberg (1981); Montú \& Gloeden (1986); Bradford-Grieve, et al (1999); Dias \& Araujo (2006).

\section{Observação}

Para o registro de espécies do gênero Oithona, a utilização dos poros no cefalossoma vem sendo discutido como característica taxonômica nos machos (Rocha, 1986).

\section{Família Cyclopidae \\ Subfamília Eucyclopinae \\ Espécie Eucyclops serrulatus (Fischer, 1851)}

(Figura 15)

A
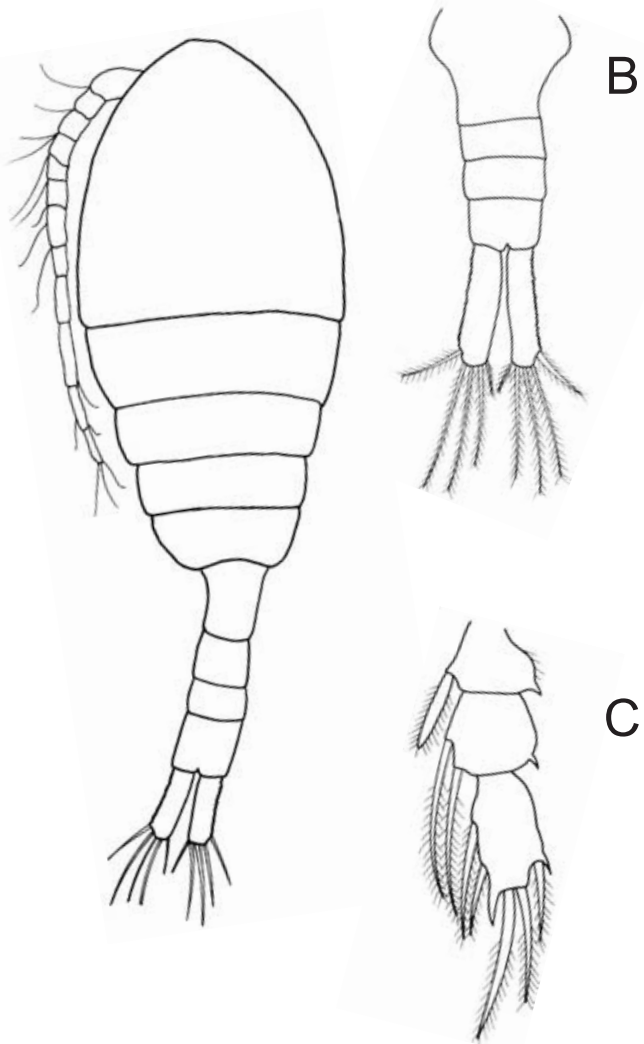

Figura 15 - Eucyclops serrulatus - (A) fêmea; (B) urossoma; (C) endópodo da quarta pata.

\section{Diagnose}

Corpo pequeno e oval, prossoma e urossoma nitidamente separados, antena com 11 ou 12 segmentos. Ramo caudal da fêmea é cerca de 5 vezes mais longo que largo e apresenta espínulos (serra) ao longo da margem externa, enquanto que a margem interna é lisa. P1 a P4 são trisegmentadas.

\section{Ecologia}

Espécie oligohalina (0-14) e estenotérmica (16$22^{\circ} \mathrm{C}$ ), euritópica com maior densidade em condições de vazante.

\section{Distribuição}

Cosmopolita em ambientes dulcícolas na América do Sul.

\section{Literatura}

Reid (1985); Dussart \& Defaye (1995).

\section{Observação}

Para o registro de espécies do gênero Eucyclops, recomenda-se checar também a placa coxal da $\mathrm{P} 4,0$ receptáculo genital da fêmea e o basípodo da antena (face frontal e caudal) (Lansac-Tôha et al, 2002).

\section{CONSIDERAÇÕES FINAIS}

No estado de Santa Catarina, os estudos que abordam a comunidade planctônica dos seus sistemas aquáticos, como no baixo estuário do rio Itajaí-açu, focam os aspectos biológicos e ecológicos, havendo então uma carência de estudos que priorizem as informações taxonômicas dos organismos. Portanto, estes estudos devem ser incentivados, pois são importantes sob o ponto de vista da conservação da biodiversidade, do manejo dos ecossistemas e da solução de problemas que aceleram a perda da diversidade biológica, como conseqüência de variados impactos, particularmente, nos sistemas aquáticos que estão sob contínua e crescente degradação de sua qualidade ambiental como é o caso do sistema fluvial do rio Itajaí-açu e de outros na região.

\section{AGRADECIMENTOS}

Os autores agradecem a Oceanógrafa Renata Nunes e a acadêmica Laura Vigliar pelo auxílio na separação de organismos zooplanctônicos a serem inseridos no atlas. Ao acadêmico Paulo Oscar Graf pelo auxílio em desenhos de organismos descritos e a Oceanógrafa Suzana Guedes pelo auxílio no programa ArcMap para criação do mapa da área de estudo. Ao Biólogo Muriel Amaral e ao acadêmico José Bicca pela realização das campanhas de coleta. Aos revisores pelas enriquecedoras sugestões para elaboração desse manuscrito. 


\section{REFERÊNCIAS}

Björnberg, T.K.S. 1981. Copepoda. In: Boltovskoy, D. (ed.) Atlas del zooplancton del Atlântico Sudoccidental y métodos de trabajo con el zooplancton marino. Publ. Esp. INIDEPE, Mar del Plata. 587-679p.

Boltovskoy, D. 1981. Recuento y análisis de los datos. In: Boltovskoy, D. (ed.). Atlas del zooplancton del atlantico sudoccidental y métodos de trabajo con el zooplancton marinho. Mar del Plata: INIDEP, 1981. 153-168p.

Boltovskoy, D. 1999. South Atlantic Zooplancton. Leiden: Backhuys Publishers, 1706p.

Bradford-Grieve, J.M.; Markhaseva, E.L.; Rocha, C.E.F. \& Abiahy, B. 1999. Copepoda In: Boltovskoy, D. (ed.). South Atlantic Zooplancton. Leiden: Backhuys Publishers. 869-1098p.

Coelho-Botelho, M. J. 2003. Dinâmica da comunidade zooplanctônica e sua relação com o grau de trofia em reservatórios. CETESB - Companhia de Tecnologia e Saneamento Ambiental, Setor de Comunidades Aquáticas, SP.

COMITÊ DO ITAJAÍ. 2004. Informações sobre a bacia do Itajaí. Disponível em: http:// www.comiteitajai.org.br. Acesso em 22 de fev. 2004.

Dias, C.O. \& Araujo, A.V. 2006. Copepoda. In: Bonecker, S.L.C. (ed.). Atlas de zooplâncton da região central da Zona Econômica Exclusiva brasileira. Rio de Janeiro: Museu Nacional, 21-100p.

Dussart, B.H. \& Defaye, D. 1995. Copepoda: introduction to the Copepoda. Guides to the identification of the microinvertebrates of the continental waters of the world. Amsterdam: SPB Academic Publishing, 277p.

Elmoor-Loureiro, L.M.A. 1997. Manual de identificação de cladóceros límnicos do Brasil,: Editora Universa, UCB, Brasília. 156p.

Elmoor-Loureiro, L. M. A., Mendonça-Galvão, L. e Padovesi-Fonseca, C. 2004. New cladoceran records from Lake Paranoá, Central Brazil. Braz. J. Biol., 64 (3A):415-422.

Infante, A. G. 1988. El plâncton de las águas continentales. Washington, DC: Secretaria General de la Organización de los Estados Americanos.

Keppeler, E.C. \& Hardy, E.R. 2002. Estimativa do tamanho das fêmeas com ovos de Moina minuta Hansen, 1899 (Cladocera, Crustacea) no lago Amapá, Rio Branco Estado do Acre, Brasil. Acta Scientiarum Maringá, 24(2):321-328.

Kotov, A. A., Ishida, S. e Taylor, D. J. 2009. Revision of the genus Bosmina Baird, 1845 (Cladocera: Bosminidae), based on evidence from male morphological charecters and molecular phylogenies. Zoo. J. Linnean Soc. 156:1-51.

Lansac-Tôha, F.A.; Velho, L.F.M.; Higuti, J. \& Takahashi, E.M. 2002. Cyclopidae (Crustacea, Copepoda) from the upper Paraná river foodplain, Brazil. Braz. J. Biol., 62 (1):125-133.

Lopes, R.M. 2004. Bioinvasões aquáticas por organismos zooplanctônicos: uma breve revisão In: Silva, J.S.V. \& Souza, R.C.C.L. (eds.). Água de Lastro e Bioinvasão. Rio de Janeiro: Interciência. 113-131p.

Montú, M.A. \& Gloeden, I.M. 1986. Atlas dos Cladocera e Copepoda (Crustacea) do Estuário da Lagoa dos Patos, Rio Grande do Sul - Brasil. Pontal do Sul: UFPR. Neritica, 2(1):1-134.

Onbé, T. 1999. Cladocera. In: Boltovskoy, D. (ed.) Atlas del zooplancton del Atlântico Sudoccidental y métodos de trabajo con el zooplancton marino. Publ. Esp. INIDEPE, Mar del Plata, 799-813p.

Ramirez, F.C. 1981. Cladocera. In: Boltovskoy, D. (ed.) Atlas del zooplancton del AtlânticoSudoccidental y métodos de trabajo con el zooplancton marino. Publ. Esp. INIDEPE, Mar del Plata. 533-542p.

Reid, J.W. 1985. Chave de identificação e lista de referências bibliográficas para as espécies continentais sulamericanas de vida livre da ordem Cyclopoida (Crustácea, Copepoda). Bol. Zool. São Paulo: USP. 9:17-143.

Resgalla Jr, C.; Souza, V.G.C.; Rörig, L.R. \& Schettini, C.A.F. 2008. Spatial and temporal variation of the zooplankton community in the area of influence of the Itajaí-açu River, SC (Brazil). Braz. J. Oceanogr., 56(3):211-224.

Rocha C.E.F. da. 1986. Copepods of the genus Oithona Baird,1843 from mangrove areas of Central and South America. Hydrobiologia, 135(1-2):95-107.

Rörig, L.R. 2005. Usos múltiplos e qualidade das águas da bacia do baixo Itajaí-açu, SC. Elementos para um gerenciamento integrado. Tese de Doutorado, Pós-graduação em Ecologia e Recursos Naturais, Faculdade de Ciências Biológicas e da Saúde, Universidade Federal de São Carlos, São Carlos. 295p.

Rörig, L.R.; Resgalla Jr., C. \& Schettini, C.A.F. 2003. Estrutura da assembléia planctônica através do estuário e da pluma do rio Itajaí-açu. Blumenau. Rev. Estudos Amb., 5(1):76-94.

Schettini, C.A.F. \& Carvalho, J.L.B. 1998. Hidrodinâmica e distribuição de sólidos em suspensão no estuário do rio Itajaí-açu. Itajaí. Notas Tec. Facimar, 2:131140.

Schettini, C.A.F.; Kuroshima, K.N.; Pereira Fo., J.; Rorig, L.R., Resgalla Jr., C. 1998. Oceanographic and ecological aspects of the Itajaí-açu river plume during a high discharge period. Itajaí. Na. Acad. Brás. Ciênc. 2(70):335-351. 
Schettini, C.A.F.; Resgalla Jr., C.; Pereira Fo., J.; Silva, M.A.C.; Truccolo, E.C. \& Rorig. L.R. 2005. Variabilidade temporal das características oceanográficas e ecológicas da região de influência fluvial do rio Itajaí-açu. Itajaí. Braz. J. Aquat. Sci. Tech. 2(9):93102.

Schindler, D. W. 1987. Detecting ecosystem responses to anthropogenic stress. Ottawa, Can. J. Fish. Aquat. Sci. 44:6-25.

Serafim-Júnior, M.; Neves, G.P.; Brito, L. \& Ghidini, A.R. 2006. Zooplâncton do rio Itajaí-acú a jusante da cidade de Blumenau, Santa Catarina, Brasil. Estud. Biol., 28(65):41-50.

Veado, L.D. 2008. Variação espaço-temporal do zooplâncton do baixo estuário do rio Itajaí-açu, SC. Dissertação de Mestrado, Pós-graduação em Ciência e Tecnologia Ambiental, Centro de Ciências Tecnológica da Terra e do Mar, Universidade do Vale do Itajaí. 71pp. 